\title{
Coral Larvae Every Day: Leptastrea purpurea, a Brooding Species That Could Accelerate Coral Research
}

\section{OPEN ACCESS}

Edited by:

Thomas K. Frazer,

University of Florida, United States

Reviewed by:

Mark Q. Martindale,

University of Florida, United States

Ross Cunning

University of Hawaii, United States

*Correspondence:

Samuel Nietzer

samuel.nietzer@uni-oldenburg.de

Peter J. Schupp

peter.schupp@uni-oldenburg.de

Specialty section:

This article was submitted to

Coral Reef Research,

a section of the journal

Frontiers in Marine Science

Received: 19 December 2017

Accepted: 21 November 2018

Published: 06 December 2018

Citation:

Nietzer S, Moeller M, Kitamura M and Schupp PJ (2018) Coral Larvae

Every Day: Leptastrea purpurea, a Brooding Species That Could

Accelerate Coral Research.

Front. Mar. Sci. 5:466.

doi: 10.3389/fmars.2018.00466

\author{
Samuel Nietzer ${ }^{1 *}$, Mareen Moeller ${ }^{1}$, Makoto Kitamura ${ }^{2}$ and Peter J. Schupp ${ }^{1 *}$ \\ ${ }^{1}$ Institut für Chemie und Biologie des Meeres, Carl von Ossietzky Universität Oldenburg, Wilhelmshaven, Germany, \\ ${ }^{2}$ Okinawa Prefecture Environment Science Center, Urasoe, Japan
}

Sexually produced larvae are used in various fields of coral research. Because the vast majority of scleractinians reproduces only on one or few occasions per year through simultaneous release of gametes, and because an ex situ spawning induction is still very hard to achieve, great efforts are required to obtain planula larvae. Brooding corals have been used to harvest planulae although their larvae often differ in various traits from most spawning corals, e.g., in settlement behavior. Other cnidarians, such as Aiptasia spp., have been substituting for scleractinians in many aspects of coral research. However, organisms such as Aiptasia differ strongly from scleractinians, thus limiting the transferability of obtained results. This study examines the potential of Leptastrea purpurea as a reliable source of larvae for coral research. Larval output as well as settlement behavior of planulae was investigated. Our results show that colonies of $L$. purpurea released a daily average of $3.7( \pm 0.2)$ larvae during a period of 65 days, thus allowing continual access to planula larvae. We collected a total of 58127 larvae from our broodstock of 243 colonies. Larval settlement is induced by the same and/or similar cues as in many spawning species which increases the transferability of conclusions. We discuss the utility of $L$. purpurea for research on scleractinian physiology, ecology and larval settlement and conclude that $L$. purpurea is a well-suited organism to accelerate progress in many fields of coral research.

Keywords: coral reproduction, brooding, recruitment, settlement cues, faviid

\section{INTRODUCTION}

Throughout their distribution coral reefs are threatened by a multitude of mostly anthropogenic stressors: coral communities have to cope with the consequences of rising sea surface temperatures, overfishing, pollution, and coastal development (Hughes, 1994; Hughes et al., 2003; HoeghGuldberg et al., 2007; Huang, 2012). Elevated sea surfaces temperatures and a higher frequency and amplitude of temperature anomalies caused by ongoing climate change are particularly serious threats to coral reefs (Hughes et al., 2017). Unless carbon emissions are greatly reduced, coral reefs will experience rising temperatures throughout this century leading to significant decline of coral reef ecosystems (Hoegh-Guldberg et al., 2007). Whether or not scleractinians will be able to adapt to these rapidly changing conditions is one of the main questions and challenges in modern coral reef science.

Sexual reproduction and recruitment are highly important for both resilience and adaptability of coral communities (Edmunds, 2004; Hoegh-Guldberg, 2014). Apart from the recombination of 
parental DNA, the potential developmental plasticity of juvenile corals with respect to phenotype expression might play an important role in adaptive processes (Edmunds, 2004; Gilbert et al., 2015). The uptake and selection of suitable symbiotic dinoflagellates may be only one aspect of their plasticity (Berkelmans and van Oppen, 2006; Abrego et al., 2009; Byler et al., 2013; Yamashita et al., 2014). Acquired bacterial communities might be just as important (Reshef et al., 2006; Rosenberg et al., 2007). Since many natural and anthropogenic stressors have been studied mainly with adult colonies of various coral species, data on larvae and juvenile corals are rarely available. In a rapidly changing world that is heavily impacted by anthropogenic activities, it is crucial to study and understand the effects of disturbances on the whole life cycle, especially on larvae, recruits and juveniles of various stages (Bauman et al., 2015). Detailed knowledge of these impacts will be pivotal for planning and managing conservation efforts, such as reef restoration, and for channeling the limited available resources for reef conservation into the most effective measures.

In many disciplines of biological sciences, model organisms are used as proxies to understand certain aspects of the life cycle of an organism or a group of organisms. These model organisms facilitate a detailed insight into physiological, developmental, or behavioral phenomena. Most of these organisms are easy to culture and have a rather short life cycle allowing the production of many individuals in a narrow time frame. Fast maturing organisms enable research on possible effects of environmental or physiological manipulations on following generations.

Due to their physiology, scleractinians are generally difficult to culture over longer periods, which often requires high technical and financial efforts. It was not before the mid80 s that scleractinians were cultured successfully in an ex situ environment. Recent technological progress has made it possible to provide sufficient high-quality lighting and adequate water chemistry to meet and maintain the demands of scleractinians.

Other cnidarians that do not require such efforts are usually favored for physiological studies. Admittedly, only a small number of closely related organisms allow the study of aspects such as adaptability and reproduction. Alcyonaceans (subclass Octocorallia) have been used to examine specific traits although they are phylogenetically fairly distinct from scleractinians. Broadcast spawning and brooding alcyonaceans have been proposed as model organisms in coral research (Gleason and Hofmann, 2011). Actiniarians or anemones (subclass Hexacorallia) can also serve as model organisms to a certain extent. However, several of their physiological and ecological traits differ significantly from scleractinians although they belong to the same subclass. Aside from the most prominent difference, i.e., the lack of a calcium carbonate skeleton, some anemones like the often-used Aiptasia spp. have a higher resilience to subpar conditions (Sunagawa et al., 2009) which makes their culture relatively easy but limits direct comparisons with scleractinians. Additionally, anemones have the ability to move and change their location. Anemones of the genus Aiptasia have been successfully established as model organisms (Voolstra, 2013) and can be used to study aspects of the dinoflagellatecnidarian symbiosis. Although Aiptasia usually hosts varieties of symbionts different from those in scleractinians, they are more flexible in their choice of symbionts and can acquire the same strains as found in scleractinian corals. Aiptasia can also be reared aposymbiotically and subsequently inoculated with cultured Symbiodinium (Sunagawa et al., 2009; Lehnert et al., 2012; Thornhill et al., 2013). The culture of Aiptasia spp. is well established and can provide large amounts of biomass with relatively little maintenance and technical effort (Voolstra, 2013). However, Aiptasia and other anemones are very distinct from scleractinians in many physiological traits. Modern coral research needs scleractinians that can successfully be cultured ex situ and can meet the requirements of physiological and molecular research (Gleason and Hofmann, 2011).

The major way scleractinian corals have been propagated on a large scale in an ex situ environment is cloning by fragmentation. With this technique, it is impossible to produce genuine juvenile corals. In a time in which much hope lies on the adaptability of new coral generations, fragmentation seems to be an outdated way to produce samples for experiments concerning transgenerational research.

The majority of hermatypic coral species reproduce by synchronized broadcast spawning events that occur annually on very few occasions. Main factors inducing the synchronous spawning event are lunar cycle and length of day (Babcock and Heyward, 1986; Richmond and Hunter, 1990). Mimicking the natural environment including solar fluctuations throughout the year, the lunar cycle as well as the annual temperature profile and food availability requires advanced technical efforts and extensive experience and can induce spawning in an artificial ex situ environment. This milestone was achieved in 2014 by Jamie Craggs from the London Horniman Museum and has since been replicated many times with several species of the genus Acropora (Craggs et al., 2017). When working with spawning species, there is only a very narrow time frame ( 1 to 2 events per year and location) in which it is possible to acquire gametes and subsequently larvae, recruits and juveniles. This requires high logistical as well as financial efforts since spawning coral communities are often situated far away from sophisticated research facilities (Gleason and Hofmann, 2011).

In contrast to the broadcast spawning species, some corals reproduce by releasing fully developed larvae instead of gametes. The majority of brooding species release larvae in a temporally cyclic mode (Harrison and Wallace, 1990; Richmond and Hunter, 1990; Zakai et al., 2006), oftentimes triggered by the lunar cycle (Richmond and Hunter, 1990; Zakai et al., 2006). The time of larval release can vary depending on location (Stoddart and Black, 1985; Harrison and Wallace, 1990; Tanner, 1996; Kuffner and Paul, 2004; Tran and Hadfield, 2011). In Guam, Pocillopora damicornis and Stylophora pistillata have been observed to release larvae on a monthly basis with seasonal fluctuations (SzmantFroelich, 1985; Richmond and Hunter, 1990; Zakai et al., 2006). Other species with a lunar correlated larval release that have been subject to larval studies in the past are Agaricia spp. (Morse et al., 1988) and Favia fragum (Randall and Szmant, 2009b).

Although most brooding corals seem to release larvae in a cyclic manner, there are species known to release larvae constantly which allows continual access to brooded larvae. One 


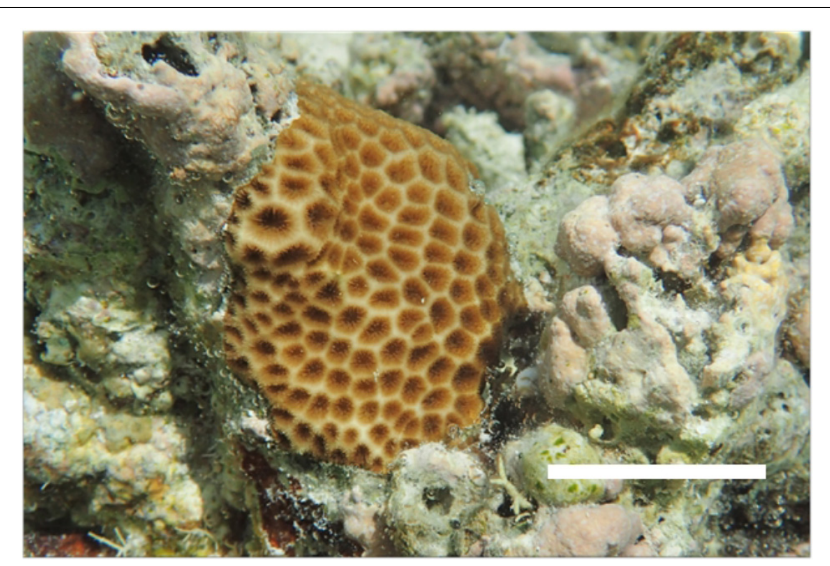

FIGURE 1 | Adult colony of Leptastrea purpurea in its typical habitat. Scale bar: $3 \mathrm{~cm}$.

such species is Stylaraea punctata (Golbuu and Richmond, 2007). However, larvae of $S$. punctata exhibit an unusual settlement behavior by avoiding crustose coralline algae (CCA). S. punctata is the smallest of all known scleractinians and has been reported to be overgrown by calcareous algae such as Hydrolithon reinboldii (Golbuu and Richmond, 2007). This unique settlement behavior could have implications for the transferability of results. Additionally, due to its small adult size, its larval output is rather low.

Another species that - at least in certain populations - releases larvae in a non-seasonal and presumably non-cyclic manner is the brooding coral Leptastrea purpurea. L. purpurea (Dana, 1846) is a faviid coral distributed from the Red Sea throughout the Indo-Pacific up to the Ryukyu island chain and Hawaii (Veron, 1993 , 2000). In Guam, colonies rarely exceed a diameter of 10 $12 \mathrm{~cm}$ (Figure 1). L. purpurea seems to be a rather generalist species and can often be found on reef flats as well as in depths of up to $40 \mathrm{~m}$. Several studies report that $L$. purpurea can cope with higher temperatures than many other species of hermatypic corals: Loya et al. (2001) observed that L. purpurea was a strong competitor after bleaching events in Okinawa (van Woesik et al., 2011). After a bleaching event in French Polynesia, L. purpurea was the least impacted of 9 monitored species (Hughes et al., 2003). It also occurs in tide pools where temperatures can reach high levels close to $32^{\circ} \mathrm{C}$ (Craig et al., 2001). In Guam, L. purpurea can be found in tide pools that can reach even higher temperatures (pers. observation, Inarajan Tide Pools, $\left.13^{\circ} 16^{\prime} 18.44^{\prime \prime} \mathrm{N}, 144^{\circ} 44^{\prime} 55.49^{\prime \prime} \mathrm{E}, 2010-2015\right)$.

Although L. purpurea has been described as a broadcast spawning species (Hayashibara et al., 1993), we have been using it in Guam to harvest brooded larvae throughout the last 14 years (Tebben et al., 2015; Moeller et al., 2017). Its ability to propagate through hermaphroditic brooding, at least in Guam, has been mentioned only scarcely in the literature (Kitamura et al., 2009). Shifts from a spawning to a brooding reproductive mode and vice versa seem to occur regularly among scleractinians within evolutionary time scales and are probably independent of the coral's phylogeny (Kerr et al., 2011). Despite its large distribution range, there are only very few reports about the reproductive mode of $L$. purpurea or other species of this genus.

In comparison to most broadcast spawning species, larvae of brooding corals often exhibit a different and less selective settlement behavior. This was observed in P. damicornis as well as in S. pistillata (Rinkevich and Loya, 1979; Fadlallah, 1983; Harriott and Banks, 1995; Putnam et al., 2008; Tran and Hadfield, 2011 and Hadfield, 2011; Sneed et al., 2014). A preference for biofilms or CCA was documented for larvae of $F$. fragum and Porites astreoides, although larvae of these species tend to settle on neutral surfaces like glass or plastic containers as well (Randall and Szmant, 2009b). Several species of the Caribbean genus Agaricia exhibited a strong preference for various CCA whereas others of the same genus seemed to be less specific (Morse et al., 1988).

In contrast to the above examples and comparable to broadcast spawning species, $L$. purpurea seems to require very specific settlement inducers. Larvae of many spawning species prefer to settle on or in the immediate vicinity of CCA, e.g., H. reinboldii (Heyward and Negri, 1999; Negri et al., 2001). It is presumed that chemical cues released by specific biofilms on the alga's surface and maybe even the alga itself can be detected by the coral larvae, thus triggering a cascade of cellular processes leading to settlement and metamorphosis (Morse et al., 1988; Negri et al., 2001; Kitamura et al., 2007; Tebben et al., 2011; Tran and Hadfield, 2011 and Hadfield, 2011).

Settlement behavior of $L$. purpurea has been investigated in our working group by applying: bioguided fractionation. In this type of bioassay, a settlement-inducing crude extract is chemically separated into two or more fractions. These fractions are then tested for settlement response. Active fractions are chemically separated and subsequently tested again to obtain a higher chemical purity with each step. By applying this strategy, it is possible to isolate individual compounds such as luminaolide, which significantly enhanced larval settlement and metamorphosis in larvae of $L$. purpurea in presence of another H. reinboldii fraction (Kitamura et al., 2009). Luminaolide was isolated from CCA which are a preferred settlement substrate for many coral larvae.

Aside from a deeper understanding of larval settlement, closing the knowledge gap in larval and juvenile coral physiology and adaptability could substantially progress our understanding about the effects of shifts in coral reef habitats associated with global environmental change. Assessing the potential of developmental plasticity in juvenile corals in a changing environment should be highly prioritized (Torda et al., 2017). L. purpurea allows investigators to examine effects on juvenile corals of different age classes simultaneously. In a study about the impact of sedimentation on juvenile corals, we used juvenile L. purpurea of three different age classes simultaneously in one experiment to determine the time frame of highest sensitivity (Moeller et al., 2017).

In this article, we propose that $L$. purpurea is well-suited to accelerate research of coral biology. Our objectives were to (1) establish an efficient method for continuous larval, (2) examine larval physiology, (3) investigate settlement behavior of the larvae and evaluate the transferability of the findings, and (4) establish 


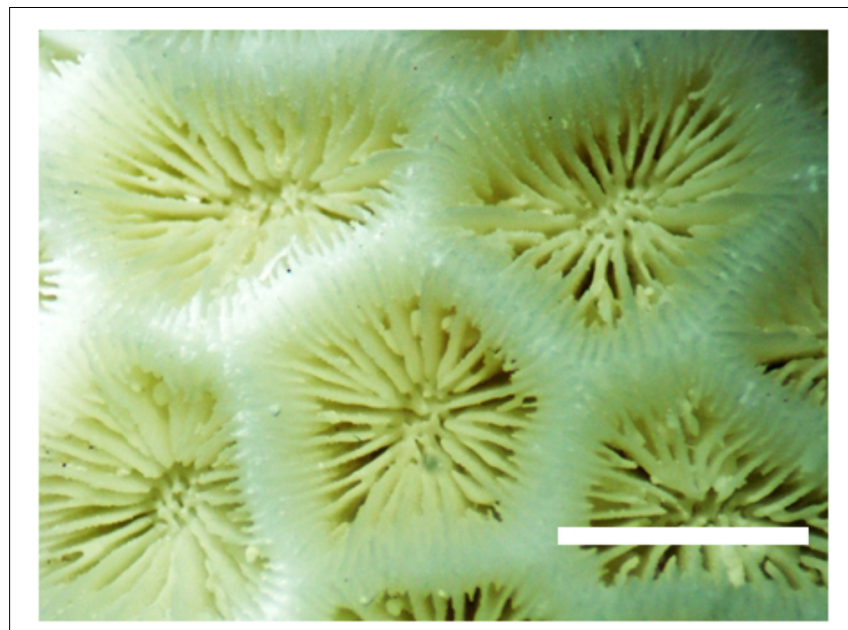

FIGURE 2 | Corallites of Leptastrea purpurea. Scale bar: 5 mm.

a method for mass production of coral recruits for scientific research.

\section{MATERIALS AND METHODS}

\section{Broodstock Collection}

To obtain coral larvae at the University of Guam Marine Laboratory (UOGML), a broodstock of mature coral colonies was needed. Adult colonies were collected at Luminao Reef, Guam, United States $\left(13^{\circ} 27^{\prime} \mathrm{N} 144^{\circ} 38^{\prime} \mathrm{E}\right)$. L. purpurea is very abundant on this particular reef flat at a depth from 1 to $3 \mathrm{~m}$. Collection of the corals was carried out under the coral collection permit issued by local authorities. The collection for this study took place on August 12th, 2014. Colonies of $4-12 \mathrm{~cm}$ in diameter were carefully detached from the substrate using hammer and chisel while free-diving. A total of 248 colonies were collected and brought ashore in a mesh bag. The corals were then transported from the location of collection in a cooler filled with seawater. Upon arrival at UOGML, all colonies were placed in a large flow-through tank $(3500 \mathrm{~L})$ in order to acclimate for a few days. Freshly hatched Artemia nauplii were offered every other night. To prepare colonies for proper identification, coral tissue and organic material were removed from five colonies by submerging the corals in 1:1 diluted chlorine bleach for 2 days. Identification of the corals as L. purpurea was performed by comparison of the skeleton to syntypes of the Smithsonian Online Repository. A close-up picture of its corallites is shown in Figure 2. Dissection of decalcified polyps confirmed that the examined colonies were hermaphroditic.

\section{Obtaining Larvae}

To quantify larval output, we documented the number of larvae released from our colonies over a 65-day period. To guarantee safe and gentle handling, the corals were placed onto trays cut out of plastic grate with a $1.5 \mathrm{~cm}$ grid which fitted into plastic boxes of 20-30 liters volume. Handles made from cable ties were

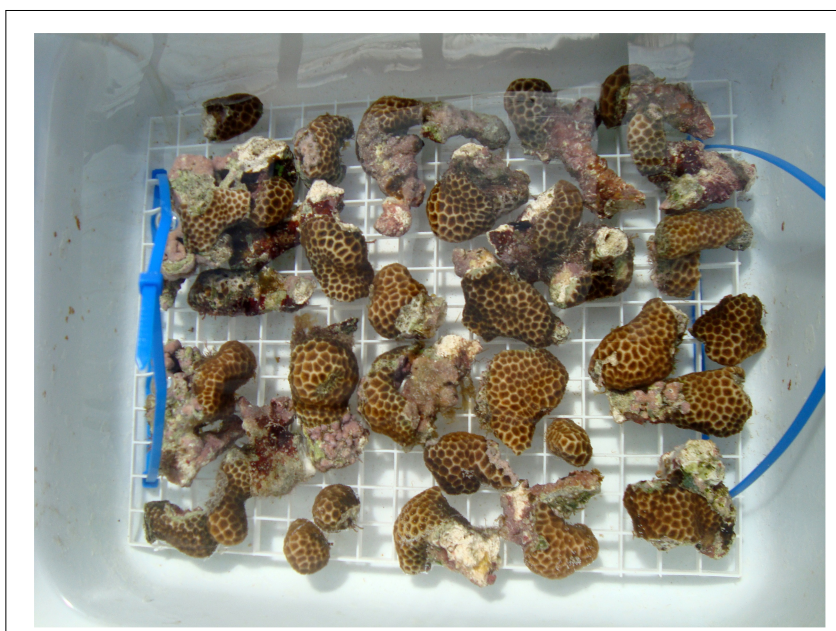

FIGURE 3 | Adult colonies placed onto an egg-crate tray to minimize handling.

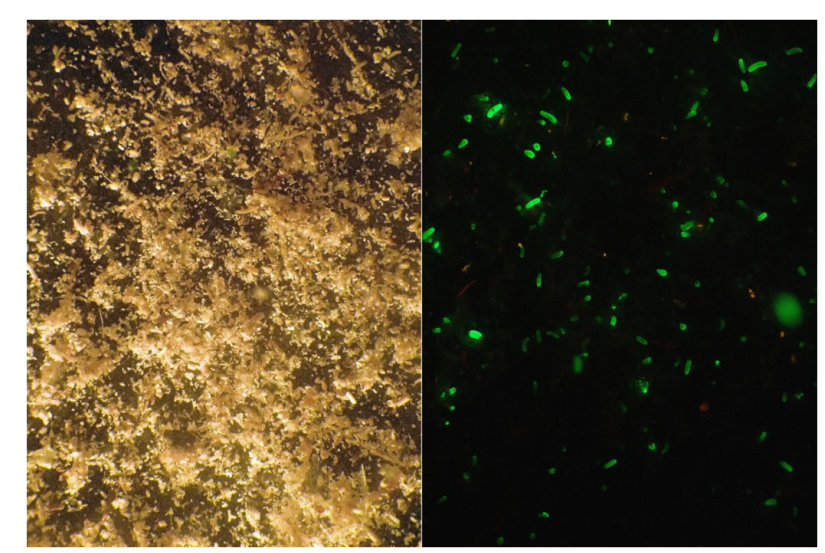

FIGURE 4 | Material from the collection container retained by a $30-\mu \mathrm{m}$ mesh. (Left) Full spectrum halogen light. (Right) Fluorescent blue light, photograph taken through a yellow barrier filter. Both photos depict exactly the same frame. The GFP helps to spot the larvae among the detritus and other matter.

attached to the trays to allow easy lifting. Before sunset, the boxes were filled with seawater and the trays were placed into the boxes as shown in Figure 3. A large, flow-through tank was used as a water bath to maintain the ambient seawater temperature of $28^{\circ} \mathrm{C}$. Each box was equipped with two $6-\mathrm{mm}$ air tubings to provide water circulation and gas exchange. The bubble rate was set to at least 3 bubbles per second. Every 3 days, the colonies were fed at nighttime with freshly hatched brine shrimp nauplii (ca. 10 nauplii per $\mathrm{ml}$ ).

About $15 \mathrm{~h}$ later, the trays accommodating the adult colonies were gently shaken and returned to the flow-through tank. The water in the boxes was filtered through a $30-\mu \mathrm{m}$ plankton mesh and the retained material was collected in a glass bowl from which larvae were collected. Since larvae of $L$. purpurea range from 0.2 to $0.9 \mathrm{~mm}$ in length, no magnification was needed. L. purpurea planulae contain a green fluorescent protein(GFP), which enables 


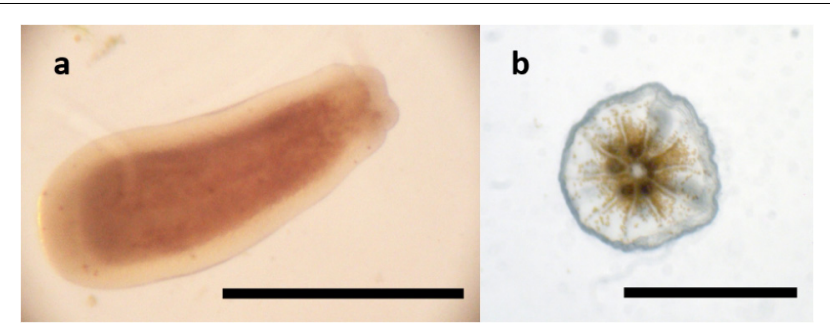

FIGURE 5 | Planula of Leptastrea purpurea (a) and primary polyp (b). Scale bar: $0.5 \mathrm{~mm}$.

convenient collection of larvae by using fluorescent blue light (510-530 nm wavelengths) and a yellow barrier filter to detect them (NIGHTSEA BlueStar) as shown in Figure 4. Both photos depict exactly the same frame. The larvae were picked with a pipette and collected in a glass beaker. Larvae could be kept in filter-sterilized seawater for several weeks if the water quality was maintained at a high level. The daily collection period in 2014 lasted from August 16th until October 19th. Larval yield was documented throughout the collection period to detect periodicity.

\section{Size and Symbiont Content of Larvae and Primary Polyps}

To assess size variation and dinoflagellate symbiont content, larvae were measured using a microscope with an optical scale. Exposing the larvae to cooler temperatures for a few minutes reduced their swimming speed and simplified measuring.

Due to their usually tubular shape (see Figure 5), larvae were measured both horizontally and vertically. The length (sagittal axis) was used for analysis. To count their symbionts, larvae were positioned and triturated between a glass slide and a cover slip. All visible symbionts were counted individually.

To count the symbionts of settled recruits, the latter were first measured (diameter of corallites) and then removed from the substrate with a pipette or a cannula. The tissue was homogenized in $100 \mu \mathrm{l}$ seawater. Subsamples of this tissue emulsion were examined with a hemacytometer to count dinoflagellate symbionts. From each sample, three subsets were taken, and symbionts were counted in a hemacytometer (Neubauer Improved). The counts of the subsamples were used to calculate the total symbiont content. When the counting could not be carried out directly after homogenization, the symbionts were preserved in the emulsion by adding Lugol's solution.

\section{Settlement Induction}

We exposed larvae to different substrates to observe which substrates or chemical compounds trigger settlement and metamorphosis. In all assays, "settlement" was defined as the complete process of attachment of the larva to the substrate surface and subsequent metamorphosis into a primary polyp with a visible oral opening.

Settlement assays were conducted in 6-well plates. One set of experiments was carried out in glass dishes to test glass as a settlement substrate. Wells were stocked with settlement substrates or chemical cues and filled with $10 \mathrm{ml}$ of filter-sterilized seawater. Chips of the coralline alga $H$. reinboldii were used as positive controls. Filter-sterilized seawater $(0.2 \mu \mathrm{m})$ was used as negative control.

Ten larvae were added per well. The assays were carried out at $28^{\circ} \mathrm{C}$ (ambient ocean temperature in Guam) and a $12 / 12 \mathrm{~h}$ light-dark cycle. Metamorphosis and settlement rates were documented after 24 and $48 \mathrm{~h}$. All experiments in this subsection were replicated six times.

To test if settlement was induced by certain coralline algae, assays were conducted with three coralline red algae common in Guam: H. reinboldii, Pneophyllum conicum, Neogoniolithon sp. The algae were broken into chips of circa $5 \mathrm{~mm}$ in diameter and rinsed with seawater. Three of these chips were added to each well as described above.

One series of experiments was designed to investigate the importance of the CCAs' biofilm for settlement induction. Prior to the assays, $H$. reinboldii chips were treated with one of three types of antibiotics for $24 \mathrm{~h}: 1 \mathrm{mM}$ penicillin, $1 \mathrm{mM}$ chloramphenicol, and $0.5 \mathrm{mM}$ streptomycin. Subsequently, the chips were rinsed three times with FSW before being used in settlement experiments. Additionally, chips of $H$. reinboldii were autoclaved, rinsed and then tested. We also offered sun-dried chips of $H$. reinboldii as settlement substrate: one set of chips was offered directly after drying, another set was kept in a flow-through tank with unfiltered seawater for 4 weeks. This allowed a natural biofilm to form on the surface of the CCA skeleton before being used in the settlement assay.

Screening for settlement inducing activity also included tetrabromopyrrole (TBP), a settlement-inducing cue which originally had been isolated from a CCA associated Pseudoalteromonas bacterium (Tebben et al., 2011). Synthetic TBP (provided by J. Tebben) dissolved in DMSO was tested in the following dilutions for $24 \mathrm{~h}$ : $1: 10,1: 100,1: 1000$, and 1:10000. The concentration of TBP in the stock solution was unknown, as described in Tebben et al. (2011).

\section{Settlement Behavior of Larvae of Different Ages}

To investigate if larval age has an influence on settlement behavior, settlement assays with larvae of three age classes (1 day, 1 week, and 2 weeks) were conducted. Larvae were stored in glass beakers of 300-ml filter-sterilized seawater at a temperature of $28^{\circ} \mathrm{C}$. Each beaker was stocked with 100 larvae. To prevent premature settlement or significant mortality during storage, it was crucial to maintain a high water quality. By conducting daily water changes with filter-sterilized seawater and transferring larvae into clean and biofilm-free beakers every other day, larvae could be kept alive and healthy for up to 4 weeks depending on maintenance effort. Water changes were conducted with a 30$\mu \mathrm{m}$ mesh and a siphon. $H$. reinboldii was offered as settlement substrate and assays were performed as described above. These settlement assays were replicated five times. 


\section{Recruit Production}

Settling and raising recruits was conducted to develop a protocol for producing primary polyps which can be used in experiments. Coral rubble (mainly Acroporidae) overgrown with $\mathrm{H}$. reinboldii was collected at Luminao Reef and broken into small pieces using a hammer. These pieces $(5-10 \mathrm{~mm}$ in diameter) were rinsed thoroughly to remove fine particles. Circa 150 larvae and about twice the number of CCA pieces were given into 2- $\mathrm{L}$ glass bowls and incubated at $28^{\circ} \mathrm{C}$ and a natural light cycle. In total, six of these bowls were set up. A 6-mm air tube generating an aeration of 1 bubble per second provided slight water movement and gas exchange. Water changes of $50 \%$ were conducted the next day. After $48 \mathrm{~h}$, all CCA pieces were examined under a dissecting microscope using fluorescent blue light as well as a common halogen lamp. Pieces harboring metamorphosed recruits were then glued with two-component epoxy glue onto tiles of the desired size and subsequently placed into a flow-through seawater tank. After the epoxy glue had hardened $(12 \mathrm{~h})$, the recruits could be used for experiments. To obtain older recruits, the tiles were hung vertically in flowthrough tanks. The tanks had a volume of ca. $500 \mathrm{~L}$ and the flow-through rate was set at $100-150 \mathrm{~L}$ per hour. Water temperature was about $28^{\circ} \mathrm{C}$ since ocean water was pumped directly into the flow-through system. For this study, a total of 767 recruits were distributed among three tanks and reared for 1 month.

Especially within the first weeks it was crucial to generate sufficient water movement. We usually set the circulation rate to 30 times the container volume per hour using aquarium circulation pumps. Growth of primary polyps was documented by measuring the polyps with a microscope scale bar. During measurement, the polyps contracted their tentacles allowing the corallites to be measured also. The soft tissue such as tentacles was not measured or quantified otherwise.

\section{Data Analysis}

Statistical analysis was conducted with IBM SPSS Statistics 21 and Microsoft Office Excel 2010. The absolute data such as the total number of settled larvae were first converted into relative data. The data were then arcsine-transformed and tested for normality (Shapiro-Wilk test). To check for a significant influence of the tested cues or factors such as larval age on settlement behavior, a one-factorial ANOVA with Tukey's Test as a post hoc test was performed. Descriptive statistical data are reported as mean and standard error $( \pm \mathrm{SE})$. Significance level was $p<0.05$.

\section{RESULTS}

\section{Husbandry of Broodstock and Obtaining Larvae}

We rarely lost any of the broodstock colonies. The initial survival after collection and acclimatization to the conditions at UOGML was $>99 \%$. After collecting larvae for several weeks to months, some colonies suffered partial tissue loss. Tissue loss was observed to be usually caused by the following factors, in order of likelihood: Aiptasia spp. damaging colonies through nematocyst contact, colonies touching each other, growth of macroalgae or cyanobacteria in direct vicinity of the coral, inadequate light conditions or insufficient water circulation.

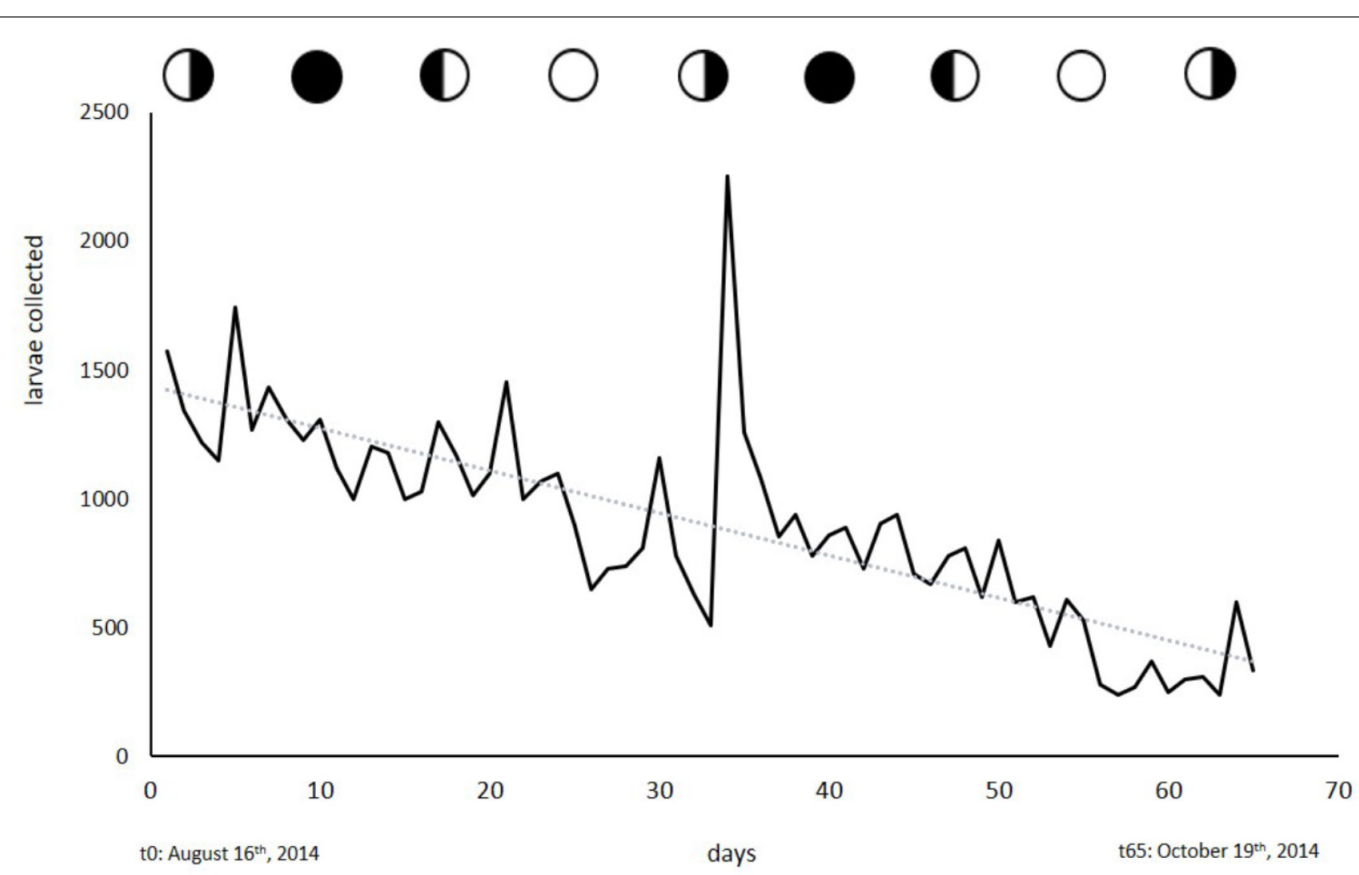

FIGURE 6 | Larvae collected from the broodstock of 243 colonies. Circles indicate moon phases. Collection started on August 16 th, 2014 and ended on October 19th, 2014. 


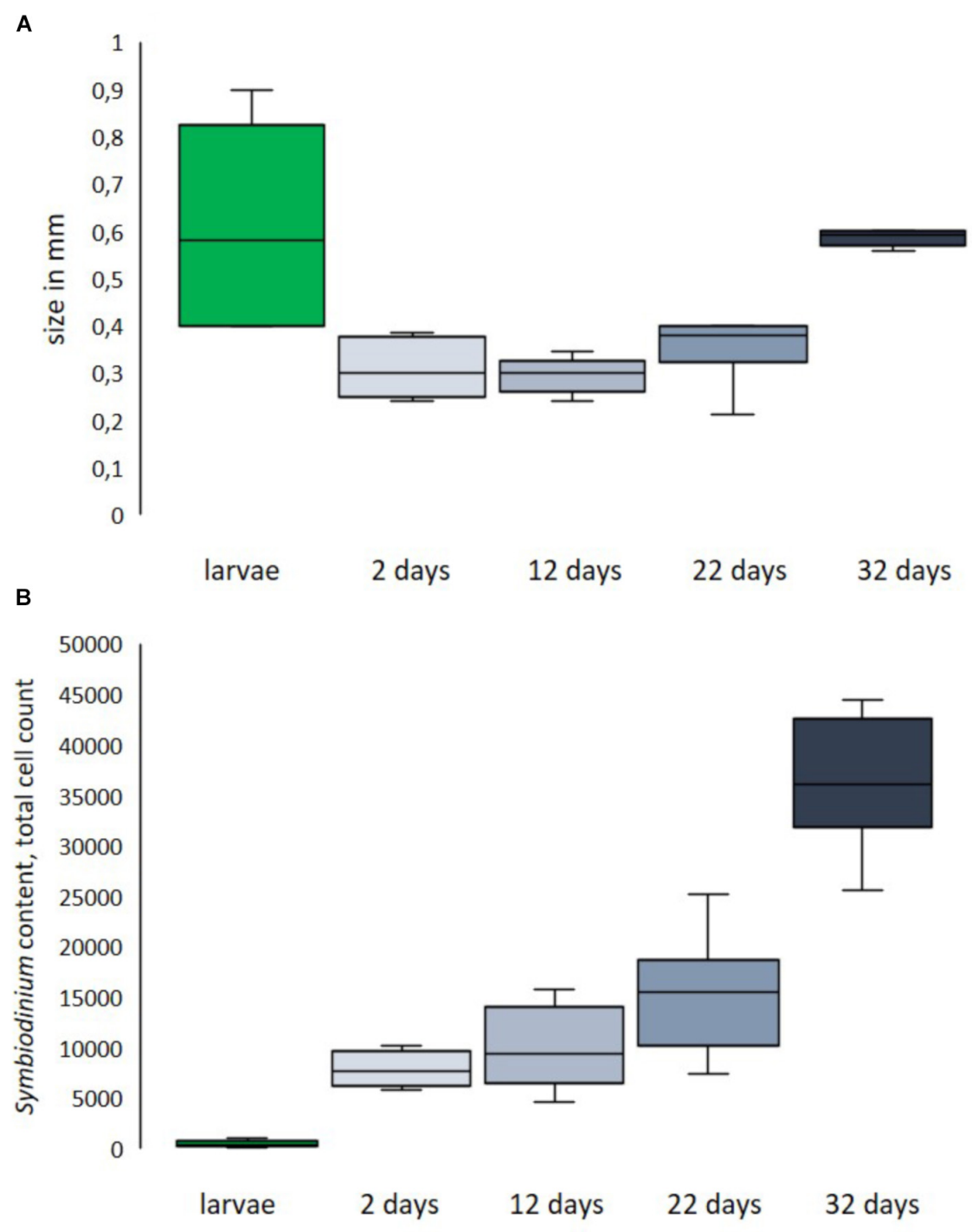

FIGURE 7 | Size distribution (A) and symbiont content (B) of fresh larvae and primary polyps of different ages post-settlement. Size of larvae is length, size of recruits is corallite diameter.

No cyclic pattern in the release of planula larvae was observed. Larvae could be obtained on any day throughout the collection period as is shown in Figure 6. The broodstock of 243 colonies often yielded 1000 larvae or more per day until production stagnated, presumably due to handling-induced stress and damage by the factors mentioned above. In the 2014 collection phase, daily larval output averaged $3.8( \pm 0.32 \mathrm{SE})$ larvae a day per colony $(6-10 \mathrm{~cm}$ in diameter). We were able to obtain a total of 58127 larvae at an average of 894 ( $\pm 49.2 \mathrm{SE}$ ) larvae per day over a time span of 65 days.

\section{Size and Symbiont Content of Larvae and Primary Polyps}

Larvae of $L$. purpurea can vary greatly in both size and dinoflagellate symbiont content. Compared to many other corals,
L. purpurea larvae are small with a documented length of $0.2-$ $0.9 \mathrm{~mm}(\mathrm{avg}=0.40 \pm 0.07 \mathrm{SE}, n=14)$. Larvae considered normal in shape and size $(\geq 0.4 \mathrm{~mm})$ measured $0.61( \pm 0.07 \mathrm{SE}) \mathrm{mm}$ in length and $0.34( \pm 0.03 \mathrm{SE}) \mathrm{mm}$ in width (see Figure 7A). The previously mentioned type of small, round larvae measured $0.20( \pm 0.03 \mathrm{SE}) \mathrm{mm}$ in length and $0.23( \pm 0.02 \mathrm{SE}) \mathrm{mm}$ in width. The observed majority of larvae contain zooxanthellae. We enumerated dinoflagellate symbionts associated with freshly released larvae and found the total amount ranged from 0 to 1134 per larva. On average, examined larvae hosted $543( \pm 293$ $\mathrm{SE}, n=7)$ symbionts. However, we found that the small larvae $(<0.4 \mathrm{~mm}$ in length) contained very few or no symbionts $(6 \pm 5$ $\mathrm{SE}, n=7)$. Two days after settlement, recruits contained 7889 $( \pm 702,7 \mathrm{SE}, n=6)$ symbionts. 12-day-old recruits harbored, on average, $10028( \pm 1670,8 \mathrm{SE}, n=6)$ symbionts (see Figure 7B, $n=6)$. 


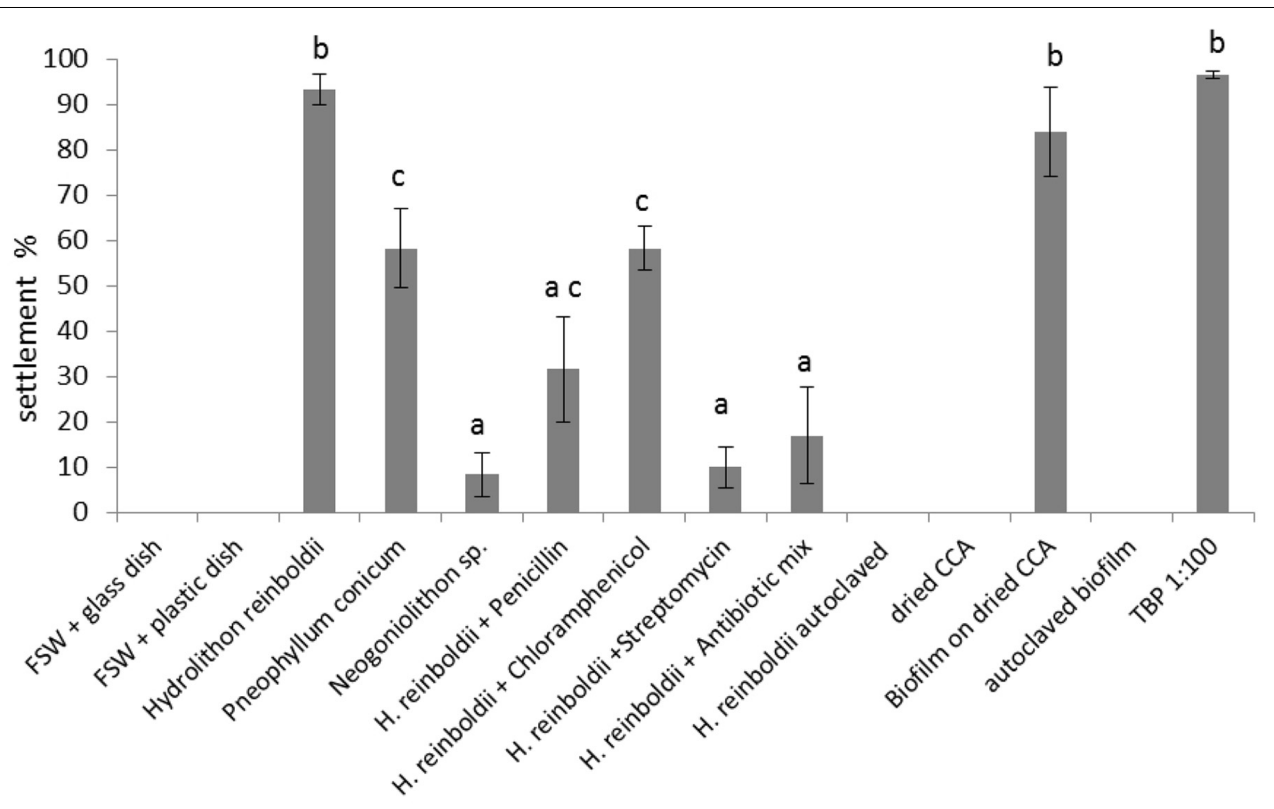

FIGURE 8 | Larval settlement in response to different substrates $(n=6)$. Error bars represent standard error (SE). Letters represent groups that differed significantly in Tukey's Test (significance level $p<0.05$ ).

\section{Settlement Behavior}

\section{Substrates}

Larvae showed very specific settlement responses to certain cues. The reported values in section "Settlement Behavior" are displayed as mean and standard error (SE). All experiments were replicated six times $(n=6)$. Unspecific settlement in filtered seawater in glass $(0 \pm 0 \%)$ or plastic $(0 \pm 0 \%)$ containers was not observed (see Figure 8).

Settlement response differed significantly among the three tested coralline algae: settlement rate on $H$. reinboldii was $93.3 \pm 3.3 \%$; P. conicum $58.3 \pm 8.7 \%$; Neogoniolithon sp. $8.3 \pm 4.8 \%$. Settlement activity on two algae differed significantly from the negative control $(H$. reinboldii $p<0.01$ and $P$. conicum $p<0.01)$.

Since $H$. reinboldii reliably induced high settlement rates, it was used for the antibiotic tests. All antibiotic treatments reduced settlement rates significantly. Chloramphenicol had the smallest impact and reduced settlement to $58.3 \pm 4.8 \%$. Penicillin had a stronger effect and larvae showed only $31.7 \pm 11.7 \%$ settlement. Settlement rates with streptomycin treated CCA were very low, i.e., $10 \pm 4.5 \%$, and did not differ significantly from the negative control ( $p=0.99)$.

Autoclaved or dried CCA did not induce settlement $(0 \pm 0.0 \%$ and $0 \pm 0.0 \%$ settlement, respectively). Dried CCA with an established biofilm, however, revealed a very high settlement rate $(84 \pm 9.8 \%)$. The 4 -week old biofilm did not differ significantly from live $H$. reinboldii $(p=0.99)$. Autoclaved biofilm showed the same results as autoclaved CCA (no settlement: $0 \pm 0.0 \%$ ).

\section{TBP}

Around $100 \%$ of the larvae showed metamorphosis when exposed to a 1:100 dilution of TBP.
Furthermore, $97 \% \pm 2.1$ of the larvae were fully attached to the well's surface and therefore showed complete settlement (attachment and metamorphosis). Higher or lower concentrations of TBP, revealed a less explicit larval response: TBP $\times 0.1$ : metamorphosis $38.0 \% \pm 11.9$, attachment $32.0 \% \pm 10.1$; TBP $\times 0.001$ metamorphosis $3 \% \pm 2.1$, attachment $2 \% \pm 0.2$; TBP $\times 0.0001$ metamorphosis $7 \% \pm 3.3$, attachment $3 \% \pm 2.1 ;$ TBP $\times 0.00001$ metamorphosis $0 \%$, attachment $0 \%(n=6)$. The exact concentration of the stock solution was unknown as described in the "Materials and Methods" section.

\section{Settlement of Different Age Classes on CCA}

There was no difference in settlement behavior among the three age classes of larvae $(p=0.90)$. Larvae that were 1 -day old showed a settlement rate of $80.0 \% \pm 5.5 \mathrm{SE}$. One-week old larvae settled at a rate of $84 \% \pm 5.1 \mathrm{SE}$ and 2-week-old larvae at $82 \% \pm 8.0 \mathrm{SE}$ $(n=5)$.

\section{Production of Recruits and Survival}

Settlement rates of larvae on fresh CCA chips $(H$. reinboldii) could reach $100 \%$ after $48 \mathrm{~h}$. The calcium carbonate skeleton was first visible through a microscope after another 2 days. Normally, $>99 \%$ of recruits survived the process of being glued onto glass or ceramic tiles and fully extended their tentacles within 1-2 h. Recruits reared for this study showed a survival of $53.6 \pm 8.48 \%$ and reached a size of 0.6 $( \pm 0.006 \mathrm{SE}) \mathrm{mm}$ after 4 weeks on average. Large numbers of undetected Aiptasia spp. and the benthic ctenophore Vallicula multiformis can reduced survival rates (unpublished data). 


\section{DISCUSSION}

The relative hardiness, habitat preferences and abundance of L. purpurea make this species very easy to collect, transport and work with. Even though L. purpurea was recorded to be a broadcast spawning species in Okinawa (Hayashibara et al., 1993; Kerr et al., 2011) we could show that it has a constant brooding behavior in Guam.

With the exception of S. punctata, L. purpurea is, to our knowledge, the only brooding coral species that constantly releases planula larvae in a non-cyclic manner. This rare reproductive behavior allows continual access to coral larvae. Over the years, we have started our larval collections at almost any time of the year and were instantly able to collect larvae. During the collection period described in this study, we collected larvae on a daily basis over the course of 65 days. Larval output slowly decreased over time $\left(R^{2} ;=0.62\right)$ but this seemed to be related to handling-induced stress, food deprivation or other stressors. We found a strong peak of larval release on September 18th, 2014, which coincidentally was an extraordinarily hot day. Strong irradiance and abnormally high temperatures can affect the water temperatures in the flow-through system at UOGML. This heat stress might have triggered the release of the exceptionally large number of larvae.

Given that the broodstock can be kept under good conditions, i.e., a flow-through system with ocean water, the collection of larvae can be conducted with very simple equipment (e.g., plastic boxes, bowls, and pipettes) and larvae can be stored for up to 4 weeks with little maintenance effort. Larvae that had been kept for 2 weeks did not show changes in their settlement behavior in our experiments. While other studies have shown an increasing settlement rate with increasing age of larvae (Burgess et al., 2009), this could not be observed in L. purpurea. This allows the keeping of larvae over a longer period of time without adverse effects on settlement. Larvae of other brooding corals (e.g., P. damicornis or S. pistillata) can only be stored for a short time: due to their unspecific settlement behavior these larvae tend to metamorphose and settle already in the beaker and most other available substrates, rendering them inadequate for determining settlement cues (Fadlallah, 1983; Putnam et al., 2008).

We were able to show that larvae of $L$. purpurea need specific cues to induce metamorphosis and settlement. Neutral substrates such as glass, plastic, dried, or autoclaved CCA did not induce settlement or metamorphosis. Live fragments of $H$. reinboldii induced very high settlement rates. One of the other two tested coralline algae, $P$. conicum induced settlement and metamorphosis as well, but to a lesser extent. Neogoniolithon sp. did not have a significant effect on settlement behavior. We observed that larvae of L. purpurea settle preferably on the breakline and not directly on top of the alga. This choice of locality could reduce a competitive situation between coral and alga. However, this was an observation during the settlement assays and was not tested statistically on its own.

Settlement assays in which sun-dried $H$. reinboldii was allowed to develop a 4-week old biofilm in flow-through natural seawater, revealed that biofilms, in general, can be very potent inducers of larval settlement as well. Treatment

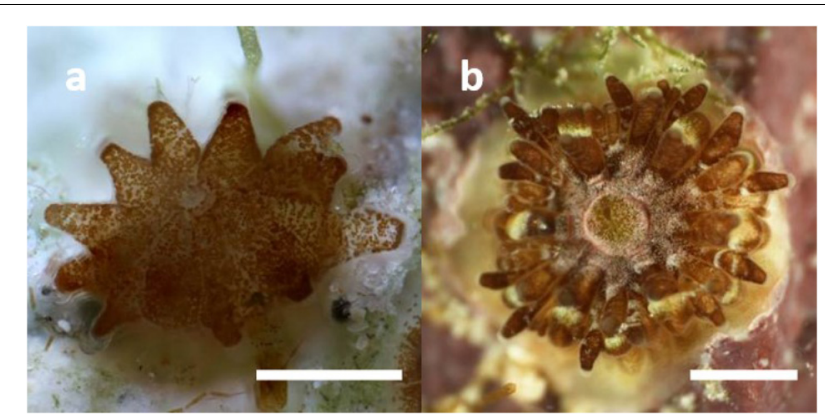

FIGURE 9 | Recruits of 4 weeks (a) and 8 weeks (b) post-settlement. Scale bar: $1 \mathrm{~mm}$. Permission to publish these photographs has been obtained from Moeller et al. (2017).

of settlement-inducing biofilms with antibiotics (penicillin, streptomycine, and chloramphenicol) resulted in a significant reduction in L. purpurea larval settlement (Figure 7).

Certain strains isolated from biofilms seem to release compounds that can be detected by larvae (Negri et al., 2001; Kitamura et al., 2007). These biofilms have been subject to several studies in which bacterial strains were isolated and tested for settlement induction. Depending on the species of coral, the number of inducing bacteria can vary greatly. Grasso et al. (2011) found that 4 out of 220 isolates induced settlement in Acropora millepora. Tran and Hadfield, 2011 and Hadfield (2011) used larvae of $P$. damicornis and found that 40 of 52 tested isolates induced metamorphosis and settlement. The group of Pseudoalteromonas bacteria contains several strains that play a key role in the settlement and metamorphosis not only of corals (Tebben et al., 2015), but also of other marine invertebrates (Huang et al., 2012). Pelagic larval stages are very common among marine invertebrates. A large number of these seem to rely on certain cues produced by biofilms to detect a suitable habitat (Hadfield, 2011).

The compound Tetrabromopyrrole (TBP) was isolated from a Pseudoalteromonas sp. originating from CCA. TBP induced metamorphosis, but not attachment in A. millepora (Tebben et al., 2011). In the Caribbean corals $P$. astreoides, Orbicella franksi and Acropora palmata, however, TBP induced full settlement with both attachment and metamorphosis, although at fairly high concentrations (Sneed et al., 2014).Our experiments with TBP showed that the settlement behavior of L. purpurea follows similar cues and pathways as the above mentioned Caribbean species. In L. purpurea, exposure to TBP significantly increased both settlement and metamorphosis. In a series of experiments with several species of Acropora (A. digitifera, $A$. humilis, and $A$. surculosa) the same effects were observed as described by Tebben et al. (2011): metamorphosis was significantly increased whereas attachment rates were rather low (Tebben et al., 2015; Kitamura et al., 2011, 2012, 2013, unpublished).

Although most larvae of $L$. purpurea already host dinoflagellate symbionts which they inherit from their parental colony through vertical transfer, symbiont density within larvae 
can vary significantly. We found small planulae that did not host any symbionts. However, these settled normally and transformed into primary polyps. After several weeks in a flow-through seawater system, these polyps had clearly taken up symbionts, indicating that symbiosis in L. purpurea is not static. Several studies documented a variety of symbiont strains hosted by L. purpurea: in depths of about 10 to $20 \mathrm{~m}$, Symbiodinium Clade C1F was found (LaJeunesse et al., 2004) whereas other surveys detected the clade C1b (LaJeunesse et al., 2004), C7 (Lien et al., 2013) as well as a variety of clade C and clade D symbionts (Fabricius et al., 2004). L. purpurea could therefore be a good candidate to study host-symbiont interactions in juvenile corals. Currently, Aiptasia diaphana and A. pallida serve as model organisms for the physiology of anthozoans including the dinoflagellate-cnidarian symbiosis (Sunagawa et al., 2009; Lehnert et al., 2012; Thornhill et al., 2013; Voolstra, 2013). Although anemones are closely related to scleractinians, they still differ in many aspects, particularly in their physiology (Lehnert et al., 2012). Progress in coral research could be accelerated by an actual scleractinian model organism or a species that enables researchers to obtain results that could be transferred more aptly to other scleractinian species. Our research with L. purpurea has shown that certain results can be transferred from this brooding species to spawning species, as settlement experiments with TBP showed activity in both L. purpurea and several Acroporidae corals (Tebben et al., 2015). Experiments with the settlement enhancing agent luminaolide yielded very similar results in L. purpurea and A. digitifera, A. tenuis (Okinawa) and A. surculosa (Guam) (unpublished data, M. Kitamura).

Unlike other scleractinians, L. purpurea provides the opportunity to rear juvenile corals of different age classes independent of lunar or annual cycles. In a study investigating the impact of sedimentation on juvenile corals we used recruits of three different age classes (recently settled, 1 month old and 2 months old) simultaneously (see Figure 9). This allowed us to show that juveniles of $L$. purpurea are most sensitive to slightly increased sedimentation levels within the first 2 weeks after settlement (Moeller et al., 2017).

Before this species can serve as a model organism, several steps such as the sequencing of the full genome and the establishment of a long-term, multigenerational culture in an ex situ system need to be achieved. However, L. purpurea already provides a unique opportunity of studying the implications of changing abiotic parameters on juvenile scleractinians as well as larval ecology and physiology. The majority of scleractinian coral species reproduce by a synchronized mass spawning that takes place only once or twice every year and is induced by multiple factors such as lunar and solar cycles, temperature and availability of nutrients. A controlled induction of spawning in an artificial ex

\section{REFERENCES}

Abrego, D., Van Oppen, M. J. H., and Willis, B. L. (2009). Highly infectious symbiont dominates initial uptake in coral juveniles. Mol. Ecol. 18, 3518-3531. doi: 10.1111/j.1365-294X.2009.04275.x

Babcock, R., and Heyward, A. (1986). Larval development of certain gametespawning scleractinian corals. Coral Reefs 5, 111-116. doi: 10.1007/BF00298178 situ culture requires extensive experience and advanced logistics. As mentioned previously, the Horniman Museum London is the only institution worldwide that has repeatedly been able to induce spawning in Acropora species (Craggs et al., 2017). L. purpurea, however, could provide researchers with ready access to larvae without having to simulate lunar cycles and diurnal rhythms.

Besides studies on larval settlement, L. purpurea provides the opportunity to investigate the developmental plasticity of juvenile corals. In many organisms, juveniles exhibit a high developmental plasticity that is driven by epigenetic processes and allows the adaptation to prevalent conditions (Gilbert et al., 2015). In the context of global environmental change, this developmental plasticity could allow corals to adapt to higher temperatures.

\section{CONCLUSION}

Based on its properties, L. purpurea seems to be a very unique coral species with many homologies to broadcast spawning species as well as to other brooding corals in both physiological and behavioral traits. The availability of large numbers of larvae and coral recruits all the year round makes L. purpurea a well-suited species to conduct ecological and physiological experiments, e.g., settlement assays, and could enable new approaches in empirical coral research. It could also allow studying the formation and physiological implications of dinoflagellate-scleractinian symbioses, since L. purpurea seems to be able to host various types of Symbiodinium. The simultaneous use of recruits of different age classes will increase knowledge about age-related thresholds and could help to examine the developmental plasticity of juvenile corals.

\section{AUTHOR CONTRIBUTIONS}

SN, MM, PS, and MK designed the experiments and conducted the experiments and data analysis. SN wrote the manuscript and prepared Figures 3-5, 9. MM prepared Figures 1, 2, 6-8.

\section{ACKNOWLEDGMENTS}

We thank students and staff of the University of Guam Marine Laboratory for assistance during field- and laboratory experiments. Many thanks to David Burdick and Dr. R. Randall for confirming the species' ID. We would also like to thank the reviewers for their valuable comments.

Bauman, A. G., Guest, J. R., Dunshea, G., Low, J., Todd, P. A., and Steinberg, P. D. (2015). Coral settlement on a highly disturbed equatorial reef system. PLoS One 10:e0127874. doi: 10.1371/journal.pone.0127874

Berkelmans, R., and van Oppen, M. J. H. (2006). The role of zooxanthellae in the thermal tolerance of corals: a nugget of hope for coral reefs in an era of climate change. Proc. Biol. Sci. 273, 2305-2312. doi: 10.1098/rspb.2006. 3567 
Burgess, S. C., Hart, S. P., and Marshall, D. J. (2009). Pre-settlement behavior in larval bryozoans: the roles of larval age and size. Biol. Bull. 216, 344-354. doi: $10.2307 / 25548165$

Byler, K. A., Carmi-Veal, M., Fine, M., and Goulet, T. L. (2013). Multiple symbiont acquisition strategies as an adaptive mechanism in the coral Stylophora pistillata. PLoS One 8:e59596. doi: 10.1371/journal.pone.0059596

Craggs, J., Guest, J. R., Davis, M., Simmons, J., Dashti, E., and Sweet, M. (2017). Inducing broadcast coral spawning ex situ: closed system mesocosm design and husbandry protocol. Ecol. Evol. 7, 11066-11078. doi: 10.1002/ece3.3538

Craig, P., Birkeland, C., and Belliveau, S. (2001). High temperatures tolerated by a diverse assemblage of shallow-water corals in American Samoa. Coral Reefs 20, 185-189. doi: 10.1007/s003380100159

Dana, J. D. (1846). United States Exploring Expedition During the Years 1838-1842, Vol. 7. Philadelphia: Lea and Blanchard, 1-740.

Edmunds, P. (2004). Juvenile coral population dynamics track rising seawater temperature on a Caribbean reef. Mar. Ecol. Prog. Ser. 269, 111-119. doi: 10. $3354 /$ meps 269111

Fabricius, K., Mieog, J., and Colin, P. (2004). Identity and diversity of coral endosymbionts (zooxanthellae) from three palauan reefs with contrasting bleaching, temperature and shading histories. Mol. Ecol. 13, 2445-2458. doi: 10.1111/j.1365-294X.2004.02230.x

Fadlallah, Y. H. (1983). Sexual reproduction, development and larval biology in scleractinian corals. Coral Reefs 2, 129-150. doi: 10.1007/BF00336720

Gilbert, S. F., Bosch, T. C., and Ledón-rettig, C. (2015). Eco-Evo-Devo: developmental symbiosis and developmental plasticity as evolutionary agents. Nat. Rev. Genet. 16, 611-622. doi: 10.1038/nrg3982

Gleason, D. F., and Hofmann, D. K. (2011). Coral larvae: from gametes to recruits. J. Exp. Mar. Biol. Ecol. 408, 42-57. doi: 10.1016/j.jembe.2011.07.025

Golbuu, Y., and Richmond, R. H. (2007). Substratum preferences in planula larvae of two species of scleractinian corals, Goniastrea retiformis and Stylaraea punctata. Mar. Biol. 152, 639-644. doi: 10.1007/s00227-007-0717-x

Grasso, L. C., Negri, A. P., F^oret, S., Saint, R., Hayward, D. C., Miller, D. J., et al. (2011). The biology of coral metamorphosis: molecular responses of larvae to inducers of settlement and metamorphosis. Dev. Biol. 353, 411-419. doi: 10.1016/j.ydbio.2011.02.010

Hadfield, M. G. (2011). Biofilms and marine invertebrate larvae: what bacteria produce that larvae use to choose settlement sites. Ann. Rev. Mar. Sci. 3, 453-470. doi: 10.1146/annurev-marine-120709-142753

Harriott, V., and Banks, S. (1995). Recruitment of scleractinian corals in the solitary islands marine reserve, a high latitude coral-dominated community in eastern Australia. Mar. Ecol. Prog. Ser. 123, 155-161. doi: 10.3354/meps12 3155

Harrison, P., and Wallace, C. (1990). "Reproduction, dispersal and recruitment of scleractinian corals," in Ecosystems of the World: Coral Reefs, Vol. 25, ed. Z. Dubinsky (New York: Elsevier).

Hayashibara, T., Shimoike, K., Hosaka, S., Heyward, A., Harrison, P., Kudo, K., et al. (1993). Patterns of coral spawning at akajima island, okinawa, japan. Mar. Ecol. Prog. Ser. 101, 253-262. doi: 10.2108/zsj.26.209

Heyward, A. J., and Negri, A. P. (1999). Natural inducers for coral larval metamorphosis. Coral Reefs 18, 273-279. doi: 10.1007/s003380050193

Hoegh-Guldberg, O. (2014). Coral reef sustainability through adaptation: glimmer of hope or persistent mirage? Curr. Opin. Environ. Sustain. 7, 127-133. doi: 10.1016/j.cosust.2014.01.005

Hoegh-Guldberg, O., Mumby, P. J., Hooten, A. J., Steneck, R. S., Greenfield, P., Gomez, E., et al. (2007). Coral reefs under rapid climate change and ocean acidification. Science 318, 1737-1742. doi: 10.1126/science.1152509

Huang, D. (2012). Threatened reef corals of the world. PLoS One 7:e34459. doi: 10.1371/journal.pone.0034459

Huang, Y., Callahan, S., and Hadfield, M. G. (2012). Recruitment in the sea: bacterial genes required for inducing larval settlement in a polychaete worm. Sci. Rep. 2:228. doi: 10.1038/srep00228

Hughes, T. P. (1994). Catastrophes, phase shifts, and large-scale degradation of a caribbean coral reef. Science 265, 1547-1551. doi: 10.1126/science.265.5178. 1547

Hughes, T. P., Baird, A. H., Bellwood, D. R., Card, M., Connolly, S. R., Folke, C., et al. (2003). Climate change, human impacts, and the resilience of coral reefs. Science 301, 929-933. doi: 10.1126/science. 1085046
Hughes, T. P., Kerry, J. T., Álvarez-Noriega, M., Álvarez-Romero, J. G., Anderson, K. D., Baird, A. H., et al. (2017). Global warming and recurrent mass bleaching of corals. Nature 543, 373-377. doi: 10.1038/nature21707

Kerr, A. M., Baird, A. H., and Hughes, T. P. (2011). Correlated evolution of sex and reproductive mode in corals (Anthozoa: Scleractinia). Proc. Biol. Sci. 278, 75-81. doi: 10.1098/rspb.2010.1196

Kitamura, M., Koyama, T., Nakano, Y., and Uemura, D. (2007). Characterization of a natural inducer of coral larval metamorphosis. J. Exp. Mar. Biol. Ecol. 340, 96-102. doi: 10.1016/j.jembe.2006.08.012

Kitamura, M., Schupp, P. J., Nakano, Y., and Uemura, D. (2009). Luminaolide, a novel metamorphosis-enhancing macrodiolide for scleractinian coral larvae from crustose coralline algae. Tetrahedron Lett. 50, 6606-6609. doi: 10.1016/j. tetlet.2009.09.065

Kuffner, I. B., and Paul, V. J. (2004). Effects of the benthic cyanobacterium Lyngbya majuscula on larval recruitment of the reef corals Acropora curculios and Pocillopora damicornis. Coral Reefs 23, 455-458. doi: 10.1007/s00338-0040416-8

LaJeunesse, T., Thornhill, D., Cox, E., Stanton, F., Fitt, W., and Schmidt, G. (2004). High diversity and host specificity observed among symbiotic dinoflagellates in reef coral communities from Hawaii. Coral Reefs 23, 596-603. doi: 10.1007/ s00338-004-0428-4

Lehnert, E. M., Burriesci, M. S., and Pringle, J. R. (2012). Developing the anemone aiptasia as a tractable model for cnidarian-dinoflagellate symbiosis: the transcriptome of aposymbiotic A. pallida. BMC Genomics 13:271. doi: 10. 1186/1471-2164-13-271

Lien, Y.-T., Fukami, H., and Yamashita, Y. (2013). Genetic variations within symbiodinium clade $\mathrm{C}$ among zooxanthellate corals (Scleractinia) in the temperate zone of japan. Fish. Sci. 79, 579-591. doi: 10.1007/s12562-013-0623-8

Loya, Y., Sakai, K., Nakano, Y., Woesik, R., and Van, R. W. (2001). Coral bleaching: the winners and the losers. Ecol. Lett. 4, 122-131. doi: 10.1046/j.1461-0248.2001. 00203.x

Moeller, M., Nietzer, S., Schils, T., and Schupp, P. J. (2017). Low sediment loads affect survival of coral recruits: the first weeks are crucial. Coral Reefs 36, 39-49. doi: 10.1007/s00338-016-1513-1

Morse, D., Hooker, N., Morse, A., and Jensen, R. (1988). Control of larval metamorphosis and recruitment in sympatric agariciid corals. J. Exp. Mar. Biol. Ecol. 116, 193-217. doi: 10.1016/0022-0981(88)90027-5

Negri, A., Webster, N., Hill, R., and Heyward, A. (2001). Metamorphosis of broadcast spawning corals in response to bacteria isolated from crustose algae. Mar. Ecol. Prog. Ser. 223, 121-131. doi: 10.3354/meps223121

Putnam, H. M., Edmunds, P. J., and Fan, T.-Y. (2008). Effect of temperature on the settlement choice and photophysiology of larvae from the reef coral Stylophora pistillata. Biol. Bull. 215, 135-142. doi: 10.2307/25470694

Randall, C. J., and Szmant, A. M. (2009a). Elevated temperature affects development, survivorship, and settlement of the elkhorn coral, Acropora palmata (Lamarck 1816). Biol. Bull. 217, 269-282.

Randall, C. J., and Szmant, A. M. (2009b). Elevated temperature reduces survivorship and settlement of the larvae of the caribbean scleractinian coral, Favia fragum (Esper). Coral Reefs 28, 537-545. doi: 10.1007/s00338-009-0482-z

Reshef, L., Koren, O., Loya, Y., Zilber-Rosenberg, I., and Rosenberg, E. (2006). The coral probiotic hypothesis. Environ. Microbiol. 8, 2068-2073. doi: 10.1111/ j.1462-2920.2006.01148.x

Richmond, R., and Hunter, C. (1990). Reproduction and recruitment of corals: comparisons among the caribbean, the tropical pacific, and the red sea. Mar. Ecol. Prog. Ser. 60, 185-203. doi: 10.3354/meps060185

Rinkevich, B., and Loya, Y. (1979). The reproduction of the red sea coral Stylophora pistillata. II. Synchronization in breeding and seasonality of planulae shedding. Mar. Ecol. Prog. Ser. 1, 145-152. doi: 10.3354/meps001145

Rosenberg, E., Koren, O., Reshef, L., Efrony, R., and Zilber-Rosenberg, I. (2007). The role of microorganisms in coral health, disease and evolution. Nat. Rev. Microbiol. 5, 355-362 doi: 10.1038/nrmicro1635

Sneed, J. M., Sharp, K. H., Ritchie, K. B., and Paul, V. J. (2014). The chemical cue tetrabromopyrrole from a biofilm bacterium induces settlement of multiple caribbean corals. Proc. Biol. Sci. 281:20133086. doi: 10.1098/rspb.2013.3086

Stoddart, J. A., and Black, R. (1985). Cycles of gametogenesis and planulation in the coral Pocillopora damicornis. Mar. Ecol. Prog. Ser. Oldend. 23, 153-164. doi: $10.3354 /$ meps023153 
Sunagawa, S., Wilson, E. C., Thaler, M., Smith, M. L., Caruso, C., Pringle, J. R., et al. (2009). Generation and analysis of transcriptomic resources for a model system on the rise: the sea anemone Aiptasia pallida and its dinoflagellate endosymbiont. BMC Genomics 10:258. doi: 10.1186/1471-2164-10-258

Szmant-Froelich, A. (1985). Sexual reproduction of Favia fragum (Esper): lunar patterns of gametogenesis, embryogenesis and planulation in puerto rico. Bull. Mar. Sci. 37, 880-892.

Tanner, J. E. (1996). Seasonality and lunar periodicity in the reproduction of pocilloporid corals. Coral Reefs 15, 59-66. doi: 10.1007/BF01626077

Tebben, J., Motti, C. A., Siboni, N., Tapiolas, D. M., Negri, A. P., Schupp, P. J., et al. (2015). Chemical mediation of coral larval settlement by crustose coralline algae. Sci. Rep. 5, 1-11. doi: 10.1038/srep10803

Tebben, J., Tapiolas, D. M., Motti, C. A., Abrego, D., Negri, A. P., Blackall, L. L., et al. (2011). Induction of larval metamorphosis of the coral Acropora millepora by tetrabromopyrrole isolated from a Pseudoalteromonas bacterium. PLoS One 6:e19082. doi: 10.1371/journal.pone.0019082

Thornhill, D. J., Xiang, Y., Pettay, D. T., Zhong, M., and Santos, S. R. (2013). Population genetic data of a model symbiotic cnidarian system reveal remarkable symbiotic specificity and vectored introductions across ocean basins. Mol. Ecol. 22, 4499-4515. doi: 10.1111/mec. 12416

Torda, G., Donelson, J. M., Aranda, M., Barshis, D. J., Bay, L., Berumen, M. L., et al. (2017). Rapid adaptive responses to climate change inin corals. Nat. Publ. Gr. 7, 627-636. doi: 10.1038/nclimate3374

Tran, C., and Hadfield, M. (2011). Larvae of Pocillopora damicornis (Anthozoa) settle and metamorphose in response to surface-biofilm bacteria. Mar. Ecol. Prog. Ser. 433, 85-96. doi: 10.3354/meps09192 van Woesik, R., Sakai, K., Ganase, A., and Loya, Y. (2011). Revisiting the winners and the losers a decade after coral bleaching. Mar. Ecol. Prog. Ser. 434, 67-76. doi: 10.3354/meps09203.

Veron, J. (1993). Corals of Australia and the Indo-Pacific. Hawaii: University of Hawaii Press.

Veron, J. E. N. (2000). Corals of the World. Australia Institute of Marine Science. Townsville: Australian Institute of Marine Science.

Voolstra, C. R. (2013). A journey into the wild of the cnidarian model system aiptasia and its symbionts. Mol. Ecol. 22, 4366-4368. doi: 10.1111/mec.12464

Yamashita, H., Suzuki, G., Kai, S., Hayashibara, T., and Koike, K. (2014). Establishment of coral-algal symbiosis requires attraction and selection. PLoS One 9:e97003. doi: 10.1371/journal.pone.0097003

Zakai, D., Dubinsky, Z., Avishai, A., Caaras, T., and Chadwick, N. (2006). Lunar periodicity of planula release in the reef-building coral Stylophora pistillata. Mar. Ecol. Prog. Ser. 311, 93-102. doi: 10.3354/meps311093

Conflict of Interest Statement: The authors declare that the research was conducted in the absence of any commercial or financial relationships that could be construed as a potential conflict of interest.

Copyright $\odot 2018$ Nietzer, Moeller, Kitamura and Schupp. This is an open-access article distributed under the terms of the Creative Commons Attribution License (CC BY). The use, distribution or reproduction in other forums is permitted, provided the original author(s) and the copyright owner(s) are credited and that the original publication in this journal is cited, in accordance with accepted academic practice. No use, distribution or reproduction is permitted which does not comply with these terms. 